\title{
Intervención educativa en el conocimiento sobre la higienización de las manos en estudiantes de enfermería
}

\author{
Educational intervention in the knowledge about \\ hand hygiene in nursing students
}

\section{Intervenção educativa no conhecimento sobre a higienização das mãos em acadêmicos de enfermagem}

André Luiz Thomaz de Souza ${ }^{1}$, Fábio Bene², Heitor Ribeiro³, Juliano de Souza Caliari' ${ }^{4}$ Deise Aparecida Carminatte ${ }^{5}$, Angelita Maria Stabile

${ }^{1}$ Enfermeiro. Mestre em Enfermagem. Docente nas Faculdades Integradas do Vale do Ribeira, Registro, SP, Brasil. Correo electrónico: alfenas2@hotmail.com

${ }^{2}$ Enfermeiro pelas Faculdades Integradas do Vale do Ribeira, Registro, SP, Brasil. Correo electrónico:fabiomlbene@hotmail.com

${ }^{3}$ Enfermeiro pelas Faculdades Integradas do Vale do Ribeira, Registro, SP, Brasil. Correo electrónico:heitorrib@hotmail.com

${ }^{4}$ Enfermeiro. Doutor em Ciências. Docente no Instituto Federal de Passos, Passos, MG, Brasil. Correo electrónico: julianocaliari@yahoo.com.br

${ }^{5}$ Enfermeira. Mestre em Enfermagem. Docente nas Faculdades Integradas do Vale do Ribeira, Registro, SP, Brasil. Correo electrónico: deiseac@gmail.com

${ }^{6}$ Enfermeira. Doutora em Ciências Fisiológicas pela Faculdade de Medicina da Universidade de São Paulo USP Ribeirão Preto, Ribeirão Preto, SP, Brasil. Correo electrónico: angelita@eerp.usp.br

Cómo citar este artículo en edición digital: Souza, A.L.T., Bene, F., Ribeiro, H., Caliari, J.S., Carminatte, D.A., Stabile, A.M. (2019). Intervención educativa en el conocimiento sobre la higienización de las manos en académicos de enfermería. Cultura de los Cuidados (Edición digital), 23(53). Recuperado de http://dx.doi.org/10.14198/cuid.2019.53.24

Correspondencia: André Luiz Thomaz de Souza.Rua Oscar Yoshiaki Magário, 185, Jardim das Palmeiras. CEP: 11.900-000 - Registro-SP [Brasil]

Correo electrónico: alfenas2@hotmail.com

Recibido: 08/12/2018; Aceptado: 08/01/2019

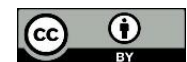

\section{ABSTRACT}

Objective: To evaluate the effect of an educational intervention on knowledge about hand hygiene in nursing students.

Method: Quasi-experimental study of the pre- and post-intervention type, carried out with 23 nursing students. Knowledge about hand hygiene was evaluated using a form containing questions about the subject. In addition, a theoretical and practical educational intervention was carried out with an average duration of 60 minutes each.

Results: The results of the pre -and postintervention comparison revealed a significant increase in the number of correct answers, with emphasis on improved knowledge related to the question: What care should be taken with the hands, nails and with the use of ornaments? 
Conclusions: The educational intervention performed in this study proved to be efficient in improving knowledge about hand hygiene.

Keywords: Nursing, patient safety, hand hygiene.

\section{RESUMO}

Objetivo: Avaliar o efeito de uma intervenção educativa no conhecimento sobre a higienização das mãos em acadêmicos de enfermagem.

Método: Estudo quase-experimental do tipo pré e pós intervenção, realizado com 23 acadêmicos de enfermagem. conhecimento sobre a higienização das mãos foi avaliado com o uso de um formulário contendo questões sobre o tema. Além disso, foi realizada uma intervenção educativa teórica e prática com duração média de 60 minutos cada.

Resultados: Os resultados da comparação pré e pós-intervenção revelaram aumento significativo no número de acertos em 17 variáveis investigadas, com destaque para melhora no conhecimento relacionado à questão: Quais os cuidados que devem ser adquiridos com as mãos, com as unhas e com o uso de adornos?.

Conclusão: A intervenção educativa realizada neste estudo mostrou-se eficiente na melhora do conhecimento sobre a higienização das mãos.

Palavras chave: Enfermagem, segurança do paciente, higienização das mãos.

\section{RESUMEN}

Objetivo: Evaluar el efecto de una intervención educativa en el conocimiento sobre la higienización de las manos en estudiantes de enfermería.

Método: Estudio cuasi-experimental del tipo pre y post intervención, realizado con 23 estudiantes de enfermería. El conocimiento sobre la higienización de las manos fue evaluado con el uso de un formulario que contenía preguntas sobre el tema. Además, se realizó una intervención educativa teórica y práctica con una duración media de 60 minutos cada una.

Resultados: Los resultados de la comparación pre y post-intervención revelaron un aumento significativo en el número de aciertos en 17 variables investigadas, con destaque para mejora en el conocimiento relacionado a la cuestión: ¿Cuáles son los cuidados que deben ser adquiridos con las manos, con las uñas y con el $\mathrm{u}$ otros el uso de adornos?

Conclusiones: La intervención educativa realizada en este estudio se mostró eficiente en la mejora del conocimiento sobre la higienización de las manos.

Palabras clave: Enfermería, seguridad del paciente, higiene de las manos.

\section{INTRODUÇÃO}

As Infecções Relacionadas à Assistência a Saúde (IRAS) estão entre as maiores preocupações na busca pela segurança do paciente (World Health Organization, 2009). No mundo, em torno de 5 a $10 \%$ das pessoas hospitalizadas terão alguma infecção relacionada ao cuidado (Yves et al., 2011). Desta forma, a prática de higienização das mãos representa uma importante estratégia para minimizar os riscos de infecções nosocomiais, devido ao baixo custo e a eficiência do procedimento (Pittet, 200; Mendonça, 2003).

Contudo, a adesão dos profissionais da saúde à prática de higienização das mãos é baixa, estima-se que menos de $40 \%$ dos profissionais a realizam de forma eficaz (Yves et al., 2011). Além disso, um estudo recente aponta o conhecimento 
insatisfatório de estudantes universitários do curso de medicina, de odontologia e de enfermagem em relação à higienização das mãos (Thakker e Jadhav, 2015). Essa situação nos remete à necessidade de ampliar ações direcionadas à educação continuada/permanente ainda no âmbito acadêmico como meta para prevenir infecções.

A contaminação das mãos de profissionais da saúde há muito tempo é apontada como uma das principais formas de transmissão de microrganismos no ambiente clínico (Pittet et al., 1999). Estudos retratam que as mãos dos profissionais da saúde podem ser colonizadas por um ou mais microrganismos, com destaque pela presença de Unidades Formadoras de Colônia de Staphylococus aureus (Bhalla, 2004; Boyce, 2007). Além das mãos, os objetos inanimados que permanecem nos serviços de saúde também representam fontes importantes de microrganismos (Felix e Miaydahira, 2009; Ferreira et al., 2011).

Desde a última década a Organização Mundial da Saúde (OMS) tem desempenhado esforços para conscientizar e ampliar a prática de higienização das mãos. Uma de suas ações envolve a campanha: "Cuidado Limpo é Cuidado Seguro" (World Health Organization, 2009; Luangasanatip et al., 2015), na qual aliado à higienização das mãos são estabelecidos cinco componentes: mudança do sistema; formação e educação; observação e feedback; lembretes no hospital e segurança hospitalar.

No Brasil, destaca-se o Programa Nacional de Segurança do Paciente (PNSP) que orienta as condutas profissionais para o monitoramento e a prevenção de danos na assistência à saúde por meio de seis ações: 1) identificar corretamente o paciente; 2) melhorar a comunicação entre os profissionais de saúde; 3) melhorar a segurança na prescrição, no uso e na administração de medicamentos; 4) assegurar cirurgia em local de intervenção, procedimento e paciente corretos; 5) higienizar as mãos para evitar infecções; e 6) reduzir o risco de quedas e úlceras por pressão (Ministério da Saúde do Brasil, 2013).

Embora ocorra todo esse esforço para aumentar a segurança do paciente $\mathrm{e}$ prevenir agravos, ainda permanecem elevadas as taxas de IRAS, principalmente nos locais onde ocorre um maior número de procedimentos invasivos, como por exemplo, nas Unidades de Terapia Intensiva (UTIs) (Barros et al., 2012; Sousa et al., 2009), expondo as pessoas a uma série de doenças infectocontagiosas, dentre elas a sepse (Martin, 2012).

Estudos sobre a higienização das mãos envolvendo estudantes universitários de enfermagem são fundamentais para o fortalecimento das práticas seguras ainda no ambiente acadêmico (Thakker e Jadhav, 2015; Felix e Miaydahira, 2009). Frente ao desafio que envolve a higienização das mãos como estratégia de assistência segura, este estudo foi desenvolvido com o objetivo de avaliar o efeito de uma intervenção educativa sobre a higienização das mãos no conhecimento de acadêmicos de enfermagem. Para tanto, como eixo norteador da pesquisa foi utilizado às recomendações da OMS (World Health Organization, 2009) para a higienização das mãos.

\section{MÉTODO}

Estudo quase-experimental do tipo pré e pós-intervenção, conduzido em agosto de 2016, com acadêmicos de enfermagem em uma instituição de ensino superior 
localizada no Vale do Ribeira, SP, Brasil. O estudo foi aprovado por um Comitê de Ética em Pesquisa com Seres Humanos (parecer $\left.\mathrm{n}^{\circ} 1.589 .996\right)$ e conduzido de acordo com os preceitos éticos conforme a resolução 466/2012 do Conselho Nacional de Saúde.

A amostra por conveniência deste estudo foi selecionada a partir dos alunos do primeiro ano letivo do curso de bacharelado em enfermagem. Foram incluídos os alunos regularmente matriculados, de ambos os gêneros, que ainda não tinham participado de aulas sobre a higienização das mãos no ensino superior. Como critérios de exclusão adotaram-se: ausência após duas tentativas de aplicação do questionário préintervenção e a não participação em todas as etapas do estudo.

$\mathrm{O}$ primeiro ano letivo do curso de enfermagem contava com $61(100 \%)$ alunos matriculados, sendo estes considerados elegíveis para estudo, no entanto, somente $23(37,70 \%)$ concluíram todas as etapas e constituíram a amostragem final. Portanto, $38(62,30 \%)$ alunos não completaram todas as etapas devido à ausência no dia da intervenção educativa e/ou na coleta de dados pós-intervenção. Desta forma, aqueles que não participaram de todas as etapas do estudo, não foram incluídos para as análises dos dados.

Para a coleta de dados foi utilizado um formulário com 15 questões divididas em duas partes: a) informações sobre os participantes do estudo: gênero, estado civil e idade; b) conhecimento sobre a higienização das mãos. $\mathrm{O}$ formulário foi submetido à validação teórica de face e exame de conteúdo por três juízes (Riccio et al., 1995; Galdeno, 2007). A aplicação do formulário ocorreu na sala de aula sob orientação dos pesquisadores deste estudo. O protocolo estabelecido na coleta de dados foi fundamentado em informações disponíveis na literatura sobre o uso de intervenções educativas (Lima et al., 2013).

O formulário foi aplicado em duas etapas: Pré-intervenção educativa: que correspondeu a coleta de dados basal referente ao conhecimento sobre a higienização das mãos e a caracterização amostral. Pósintervenção educativa: que ocorreu após 30 dias da realização da intervenção educativa sobre a higienização das mãos. Nesta etapa, Os participantes foram convidados novamente para responderem ao mesmo formulário aplicado na coleta préintervenção.

A intervenção educativa foi realizada sete dias após a coleta de dados pré-intervenção, sendo conduzida por meio de uma atividade teórica e outra prática com duração média de 60 minutos cada uma. Ambas as atividades foram desenvolvidas com o uso de um vídeo educativo publicado no The New England Journal of Medicine (Yves et al., 2011); bem como as recomendações da OMS (World Hralth Organization, 2009)) para a higienização das mãos. Ao término da intervenção educativa, cada participante recebeu um material didático sobre a higienização das mãos.

A intervenção educacional teórica foi realizada por meio de aula expositiva, com recurso audiovisual, aliado a isso a intervenção prática envolveu a demonstração dos passos realizados na higienização das mãos e dos materiais necessários. Ao final da atividade prática, todos os participantes realizaram a higienização das mãos sob a orientação dos pesquisadores e de um professor (enfermeiro) com experiência na temática deste estudo.

Os dados obtidos com a aplicação do formulário na coleta de dados pré e pósintervenção, foram tabulados e analisados por meio do programa de análise estatística 
IBM ${ }^{\circledR}$, Statistical Package for the Social Sciences, versão 20.0. Os resultados referentes às informações dos participantes do estudo foram apresentados de forma descritiva em frequência absoluta e porcentagem. Para a comparação pré e pósintervenção dos dados sobre a higienização das mãos, foi empregado o Teste Mc Nemar para amostra pareada, com significância de $5 \%$ e os valores expressos em frequência absoluta.

\section{RESULTADOS}

A distribuição dos participantes deste estudo, revela maior frequência do gênero feminino, solteiro(a) e de faixa etária até 20 anos (Tabela 1). Quando questionados se higienização das mãos previne infecção, 23 (100\%) responderam que sim. No entanto, sobre conhecer a "Campanha Salve Vidas: Higienize suas mãos", 20 (87,0\%) responderam que não conheciam.

TABELA 1: Informações sobre as características dos participantes do estudo ( $\mathrm{n}=\mathbf{2 3})$. Registro, SP, Brasil, 2016

\begin{tabular}{lccc}
\hline & Variáveis & Frequência (n) & Porcentagem (\%) \\
\hline Gênero & Masculino & 7 & 25,0 \\
\multirow{2}{*}{ Estado civil } & Feminino & 16 & 57,1 \\
& Solteiro & 14 & 50,0 \\
& Casado & 3 & 10,7 \\
\multirow{2}{*}{ Faixa etária } & União estável / amasiado & 5 & 17,9 \\
& Divorciado / separado & 1 & 3,6 \\
& Até 20 anos & 12 & 52,2 \\
& De 21 a 30 anos & 8 & 34,8 \\
& Acima de 30 anos & 3 & 13,0 \\
\hline
\end{tabular}

$\mathrm{Na}$ avaliação sobre o propósito da higienização das mãos no ambiente assistencial (ambiente no qual ocorre assistência em saúde realizada por um profissional), foi identificado aumento significativo nos acertos em relação a variável "prevenir a contaminação do ambiente" $(p=0,039)$ (Tabela 2). Ao analisar sobre quem deve realizar a higienização das mãos no ambiente assistencial, os resultados revelaram aumento significativo no número de acertos na pós-intervenção para a variável "paciente" ( $p=0,012)$ (Tabela 2).

Em relação aos materiais necessários para a "higienização das mãos" somente as variáveis: Etanol (de 75,0\% a 85,0\%) $(p=0,021)$, Isopropanol (de $75,0 \%$ a $85,0 \%$ ) $(p=0,039)$, Papel toalha (descartável) $(p=0,031)$, Secador de ar quente $(p=0,021)$, apresentaram aumento significativo no número de acertos no pós-intervenção (Tabela 2).

Quanto à técnica que pode ser utilizada para realizar a higienização das mãos, apenas variável "higienização das mãos com fricção com solução alcóolica de 20 a 30 segundos" apresentou aumento significativo na pós-intervenção $(p=0,001)$, atingindo a saturação máxima de 23 acertos (Tabela 2). 
TABELA 2: Conhecimento sobre a higienização das mãos (n=23).

"Parte 1". Registro, SP, Brasil, 2016

\begin{tabular}{|c|c|c|c|c|c|}
\hline \multirow{2}{*}{ HIGIENIZAÇÃO DAS MÃOS } & \multicolumn{2}{|c|}{ Pré-intervenção } & \multicolumn{2}{|c|}{ Pós-intervenção } & \multirow{2}{*}{ Valor - $p$} \\
\hline & Verdadeiro & Falso & Verdadeiro & Falso & \\
\hline $\begin{array}{l}\text { Qual o propósito da } \\
\text { higienização das mãos no } \\
\text { ambiente assistencial? }\end{array}$ & & & & & \\
\hline Prevenir infecções & 22 & 1 & 23 & 0 & 1,000 \\
\hline $\begin{array}{l}\text { cruzada de microrganismos } \\
\text { entre os pacientes }\end{array}$ & 20 & 3 & 23 & 0 & 0,250 \\
\hline $\begin{array}{l}\text { Prevenir a transmissão } \\
\text { direta de microrganismos } \\
\text { aos pacientes }\end{array}$ & 19 & 4 & 21 & 2 & 0,500 \\
\hline $\begin{array}{l}\text { Prevenir a contaminação do } \\
\text { ambiente }\end{array}$ & 13 & 10 & 20 & 3 & $0,039^{*}$ \\
\hline $\begin{array}{l}\text { Prevenir a aquisição de } \\
\text { infecções } \\
\text { pelos profissionais da saúde }\end{array}$ & 17 & 6 & 22 & 1 & 0,063 \\
\hline $\begin{array}{l}\text { Quem deve realizar a } \\
\text { higienização das mãos no } \\
\text { ambiente assistencial? }\end{array}$ & & & & & \\
\hline Profissionais da saúde & 22 & 1 & 23 & 0 & 1,000 \\
\hline Familiares & 17 & 6 & 21 & 2 & 0,219 \\
\hline Paciente & 12 & 11 & 21 & 2 & 0,012 \\
\hline $\begin{array}{l}\text { Pessoas que mantenham } \\
\text { contato com o paciente no } \\
\text { ambiente assistencial }\end{array}$ & 22 & 1 & 23 & 0 & 1,000 \\
\hline $\begin{array}{l}\text { Quais os materiais que } \\
\text { posso utilizar durante a } \\
\text { higienização das mãos? }\end{array}$ & & & & & \\
\hline Etanol (de $75,0 \%$ a $85 \%$ ) & 9 & 14 & 17 & 6 & $0,021^{*}$ \\
\hline $\begin{array}{l}\text { Isopropanol (de } 75,0 \% \text { a } \\
85 \% \text { ) }\end{array}$ & 3 & 20 & 10 & 13 & $0,039^{*}$ \\
\hline $\begin{array}{l}\text { N-propanol (de } 75,0 \% \text { a } \\
85 \% \text { ) }\end{array}$ & 3 & 20 & 8 & 15 & 0,125 \\
\hline $\begin{array}{l}\text { Combinação de etanol, } \\
\text { isopropanol e n-propanol } \\
\text { (de } 75,0 \% \text { a } 85 \% \text { ) }\end{array}$ & 2 & 21 & 8 & 15 & 0,070 \\
\hline $\begin{array}{l}\text { Formulações alcóolicas com } \\
\text { concentraçôes de álcool de } \\
60,0 \% \text { a } 70 \% \text { desde que } \\
\text { testadas e em conformidade } \\
\text { com normas vigentes }\end{array}$ & 16 & 7 & 19 & 4 & 0,508 \\
\hline Agua & 23 & 0 & 21 & 2 & 0,500 \\
\hline Sabão líquido & 22 & 1 & 23 & 0 & 1,000 \\
\hline Papel toalha (descartável) & 17 & 6 & 23 & 0 & $0,031^{*}$ \\
\hline Secador de ar quente & 11 & 12 & 19 & 4 & $0,021^{*}$ \\
\hline $\begin{array}{l}\text { Quais as técnicas } \\
\text { disponíveis para a } \\
\text { higienização das mãos? }\end{array}$ & & & & & \\
\hline $\begin{array}{l}\text { Higienização das mãos com } \\
\text { friccão com solucão }\end{array}$ & & & & & \\
\hline $\begin{array}{lllll}\text { alcóolica de } & 20 & \text { a } & 30 \\
\text { segundos }\end{array}$ & 12 & 11 & 23 & 0 & $0,001^{*}$ \\
\hline $\begin{array}{l}\text { Higienização das mãos com } \\
\text { água e sabão de } 40 \text { a } 60 \\
\text { segundos }\end{array}$ & 20 & 3 & 23 & 0 & 0,250 \\
\hline
\end{tabular}


TABELA 3: Conhecimento sobre a higienização das mãos (n=23).

"Parte 2". Registro, SP, Brasil, 2016

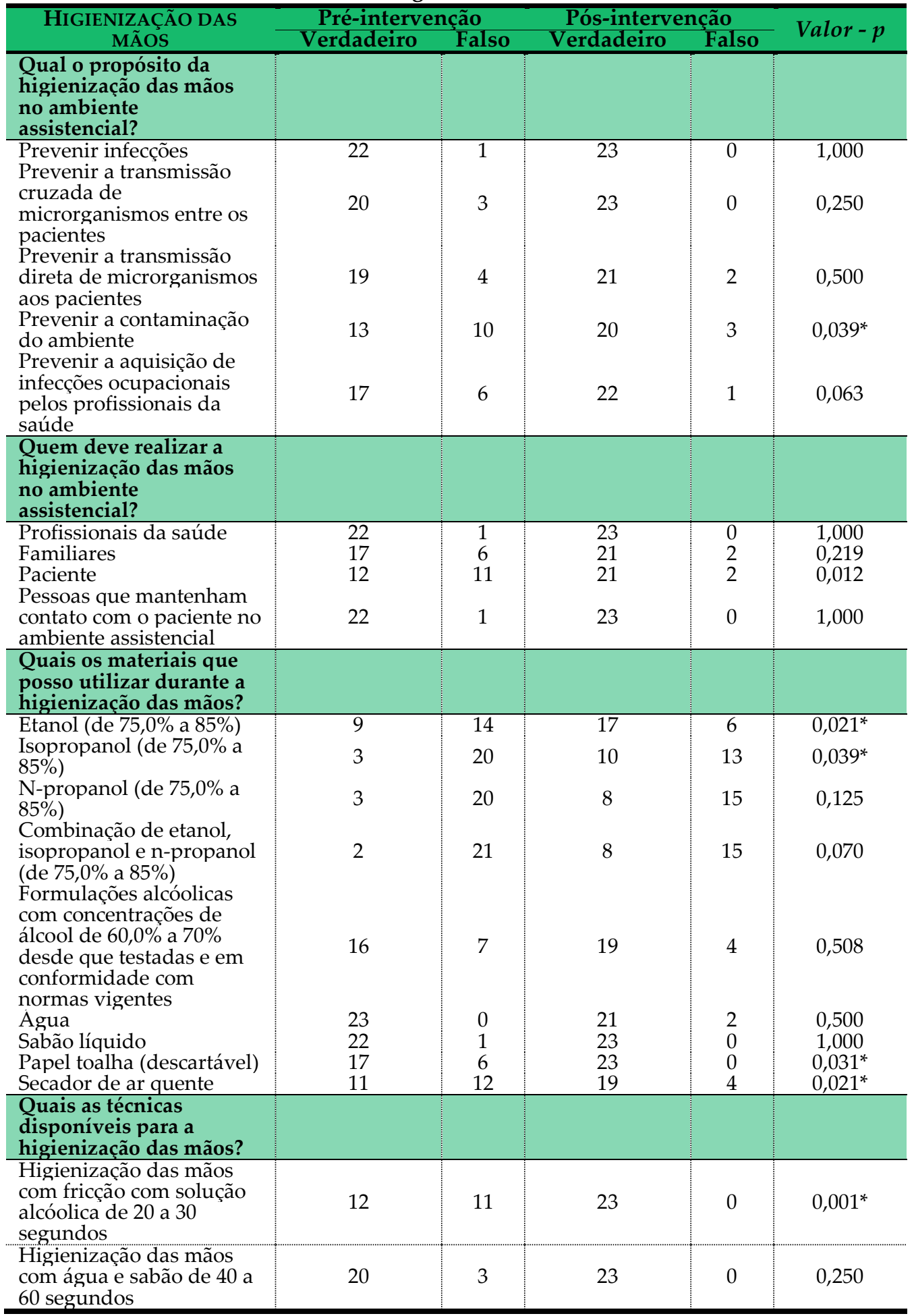


TABELA 4: Conhecimento sobre a higienização das mãos (n=23).

"Parte 3". Registro, SP, Brasil, 2016

\begin{tabular}{|c|c|c|c|c|c|}
\hline \multirow{2}{*}{$\begin{array}{l}\text { HIGIENIZAÇÃO DAS } \\
\text { MÃOS }\end{array}$} & \multicolumn{2}{|c|}{ Pré-intervenção } & \multicolumn{2}{|c|}{ Pós-intervenção } & \multirow{2}{*}{$\frac{\text { Valor }}{-p}$} \\
\hline & Verdadeiro & Falso & Verdadeiro & Falso & \\
\hline \multicolumn{6}{|l|}{$\begin{array}{l}\text { Quais os cuidados que } \\
\text { devem ser adquiridos } \\
\text { com as mãos, com as } \\
\text { unhas e com o uso de } \\
\text { adornos? }\end{array}$} \\
\hline $\begin{array}{l}\text { Não utilizar adornos } \\
\text { durante a assistência } \\
\text { clínica ao paciente }\end{array}$ & 20 & 3 & 23 & 0 & 0,250 \\
\hline $\begin{array}{l}\text { Manter as unhas com o } \\
\text { comprimento } \leq \text { a } 0,5 \mathrm{~cm}\end{array}$ & 14 & 9 & 22 & 1 & $0,021^{*}$ \\
\hline Não retirar as cutículas & 12 & 11 & 23 & 0 & $0,001^{*}$ \\
\hline $\begin{array}{l}\text { Não usar unhas artificias } \\
\text { ou extensores quando em } \\
\text { contato direto com os } \\
\text { pacientes }\end{array}$ & 16 & 7 & 23 & 0 & $0,016^{*}$ \\
\hline $\begin{array}{l}\text { Realizar tratamento para } \\
\text { as doenças ocorridas nas } \\
\text { unhas } \\
\text { Não lavar as mãos com } \\
\text { água e sabão }\end{array}$ & 17 & 6 & 21 & 2 & 0,219 \\
\hline $\begin{array}{l}\text { imediatamente antes ou } \\
\text { após realizar a } \\
\text { higienização com solução } \\
\text { alcoólica }\end{array}$ & 6 & 17 & 19 & 4 & $0,002^{*}$ \\
\hline $\begin{array}{l}\text { Não usar água quente } \\
\text { para higienizar as mãos } \\
\text { Após higienizar as mãos }\end{array}$ & 5 & 18 & 15 & 8 & $0,002^{*}$ \\
\hline $\begin{array}{l}\text { deixa-las secarem } \\
\text { completamente antes de } \\
\text { calçar luvas }\end{array}$ & 17 & 6 & 22 & 1 & 0,063 \\
\hline $\begin{array}{l}\text { Utilizar hidrante } \\
\text { (emolientes) diariamente } \\
\text { para evitar a irritação da } \\
\text { pele }\end{array}$ & 9 & 14 & 22 & 1 & $0,001^{*}$ \\
\hline \multicolumn{6}{|l|}{$\begin{array}{l}\text { Qual a finalidade no uso } \\
\text { das luvas e sua relação } \\
\text { com higienização das } \\
\text { mãos? }\end{array}$} \\
\hline $\begin{array}{l}\text { Proteger o paciente dos } \\
\text { riscos de transmissão de } \\
\text { microrganismos } \\
\text { provenientes das mãos do } \\
\text { profissional da saúde }\end{array}$ & 19 & 4 & 22 & 1 & 0,375 \\
\hline $\begin{array}{l}\text { Proteger o profissional da } \\
\text { saúde dos riscos da } \\
\text { aquisição de infecções } \\
\text { provenientes do paciente } \\
\text { O uso de luvas não }\end{array}$ & 22 & 1 & 23 & 0 & 1,000 \\
\hline $\begin{array}{l}\text { substitui a necessidade de } \\
\text { realizar a higienização } \\
\text { das mãos }\end{array}$ & 23 & 0 & 22 & 1 & 0,625 \\
\hline $\begin{array}{l}\text { A higienização das mãos } \\
\text { deve ser realizada sempre } \\
\text { antes e após a remoção } \\
\text { das luvas }\end{array}$ & 19 & 4 & 23 & 0 & 0,125 \\
\hline
\end{tabular}


Em relação aos momentos para a realização da higienização das mãos, os resultados revelaram aumento significativo, atingindo a saturação máxima (23 acertos) para a variável “após tocar objetos inanimados/superfícies próximas do paciente" ( $p=0,031)$ (Tabela 3).

Ao questionar os participantes sobre quais as vantagens nas técnicas de higienização das mãos e qual técnica escolherem, foi identificado aumento significativo no número de acertos na pós-intervenção no item solução alcoólica para a variável "utilização mais rápida e melhor tolerabilidade da pele" ( $p=0,035)$, e no item água e sabão para as variáveis "contaminação das mãos visível com fluídos corporais ou material protéico" $(p=0,004)$ e "exposição das mãos aos organismos que formam esporos (p. ex. Bacillus ou Clostridium difficileanthracis $) \quad(p=0,016)$, (Tabela 3).

Em relação ao conhecimento sobre os cuidados com as mãos, unhas e com o uso de adornos (jóias, pulseiras, relógios, dentre outros), os resultados revelaram aumento significativo no número de acertos relacionados às variáveis: manter as unhas com o comprimento total inferior a $0,5 \mathrm{~cm}$ $(p=0,021)$, não retirar as cutículas $(p=0,001)$, não usar unhas artificiais ou extensores quando em contato direto com os pacientes $(p=0,016)$, não lavar as mãos com água e sabão imediatamente antes ou após realizar a higienização com solução alcoólica $(p=0,002)$, não usar água quente para higienizar as mãos $(p=0,002)$ e utilizar hidrante (emolientes) diariamente para evitar a irritação da pele $(p=0,012)$ (Tabela 4).

Por fim, ao avaliar os efeitos da intervenção educativa sobre o conhecimento quanto à finalidade no uso das luvas e sua relação com a higienização das mãos, não foi identificado mudanças significativas entre a pré e pós-intervenção (Tabela 4).

\section{DISCUSSÃO}

Este estudo mostra que uma intervenção educativa teórica/prática sobre a higienização das mãos aumenta estatisticamente o conhecimento de acadêmicos de enfermagem. Além disso, a estratégia metodológica utilizada representa um modelo de fácil reprodução tanto no contexto acadêmico quanto no ambiente assistencial. A implementação de práticas assistências seguras requer a participação efetiva da enfermagem e isso deve fazer parte do processo de formação profissional para que o aluno incorpore em suas ações medidas focadas na prevenção de danos.

Para que ocorra um engajamento maior dos profissionais da saúde em relação à segurança do paciente, é essencial o fortalecimento da cultura da "assistência segura" (Kohn et al., 2000). Essa cultura pode ser definida como a junção de valores, competências, atitudes e comportamentos direcionados a construção de um ambiente saudável e seguro (Reis et al., 2013).

Dentre as 50 alternativas de respostas distribuídas nas oito questões sobre a higienização das mãos avaliadas neste estudo, 17 alternativas apresentaram aumento significativo no número de acertos na pós-intervenção (Tabela 2, 3 e 4). Cabe destacar que o modelo estatístico adotado neste estudo permite à comparação na proporção de respostas de cada participante, neste caso a mudança no número de erros ou acertos entre a pré e pós-intervenção (Andy, 2009).

Diferentes estratégias para a divulgação de conhecimento podem ser utilizadas com foco em obter melhores resultados no processo ensino/aprendizagem, dentre as quais se destaca: palestras, oficinas, leituras, 
conferências, material impresso e protocolos (Rabhe e Caliri, 2003). Contudo, para que o conhecimento seja utilizado na prática, o indivíduo deve ser "convencido" quanto à necessidade de mudanças em seus comportamentos (Graham e Logan, 2004).

$$
\text { Recomenda-se que programas }
$$
educacionais que busquem melhorias na prática clínica sejam implementados com frequência. Além disso, devido à possibilidade de que os efeitos de intervenções educativas sejam de curta duração torna-se fundamental que esses programas sejam reavaliados regularmente (Lima et al., 2013; Day et al., 2001).

A promoção de um ambiente assistencial seguro gera benefícios que envolvem: a diminuição de doenças e agravos, a redução no tempo de tratamento e hospitalização, a melhora funcional e a sensação de bem-estar no paciente (Constatinou e Romamiuk, 2004; Raduenz et al., 2010). Neste contexto, a enfermagem exerce um importante papel durante o planejamento de ações seguras junto à equipe multiprofissional.

Frente à problemática que envolve a segurança do paciente e, além disso, devido à baixa adesão dos profissionais da saúde na realização da higienização das mãos no contexto clínico (Yves et al., 2011), estudos que visam fortalecer o conhecimento sobre os materiais, as técnicas e os momentos para higienização das mãos são fundamentais no fortalecimento da assistência segura.

A OMS disponibiliza protocolos para melhorar a compreensão e o treinamento dos profissionais da saúde sobre a higienização das mãos (World Health Organization, 2009)). Entretanto, estes protocolos têm sido pouco utilizados nos currículos de graduação (Thakker e Jadhav, 2015). Além disso, pesquisas sobre o conhecimento dos estudantes de graduação relacionados à higienização das mãos são pouco exploradas (Thakker e Jadhav, 2015; Nair et al., 2014).

Em um estudo conduzido com 286 acadêmicos de enfermagem com o objetivo de avaliar a técnica de higienização das mãos descrita pelos graduandos e identificar a contribuição das instituições de ensino superior (IES) na formação sobre a higienização das mãos, os autores apontam que a abordagem realizada pelas IES não proporcionou conhecimento suficiente que resultasse na execução correta da técnica de higienização das mãos (Tipple et al., 2010).

Neste contexto, reforçamos que o desenvolvimento de estudos com o uso de intervenções em saúde sobre a higienização das mãos é de extrema importância no ambiente acadêmico, pois quanto mais cedo os alunos tiverem contato com a temática "segurança do paciente" maiores serão as chances de adesão depois de formados (Thakker e Jadhav, 2015).

Os resultados deste estudo devem ser avaliados com cautela, pois envolveu uma amostragem peculiar, com tamanho reduzido, o que não reflete a realidade de outros acadêmicos de enfermagem. Sugerimos o desenvolvimento de outros estudos para que se fortaleçam as evidências em relação ao uso de intervenções educativas sobre a higienização das mãos no contexto acadêmico, com o objetivo de promover desde a formação acadêmica o conhecimento com foco na prática assistencial segura e interdisciplinar.

\section{CONCLUSÃO}

A intervenção realizada neste estudo revelou ser eficiente na melhora do conhecimento sobre a higienização das mãos em acadêmicos de enfermagem, confirmando nossa hipótese alternativa, em que promoveu aumento no número de 
acertos na avaliação pós-intervenção. Acreditamos que as práticas assistenciais seguras devem ser incorporadas desde a formação acadêmica para que sejam adotadas de forma eficiente no contexto assistencial. Para tanto, é fundamental que o aluno se torne consciente sobre o seu papel enquanto futuro profissional de saúde.

\section{REFERÊNCIAS}

- Andy, F. (2009). Descobrindo a estatística usando SPSS. 2. ${ }^{a}$ ed. Porto Alegre: Artmed.

- Barros, L.M., Bento, J.N.C., Caetano, J.A., Moreira, R.A.N., Pereira, F.G.F., Frota, N.M. et al. (2012). Prevalência de micro-organismo e sensibilidade antimicrobiana de infecções hospitalares em unidade de terapia intensiva de hospital público no Brasil. Rev Cienc Farm Básica Apl. 33(3), 429-35.

- Bhalla, A. (2004). Acquisition of nosocomial pathogens on hands after contact with environmental surfaces near hospitalised patients. Infect Control Hosp Epidemiol. 25(2), 164-67.

- Boyce, J.M. (2007). Environmental contamination makes an important contribution to hospital infection. J Hosp Infect. 65(Suppl. 2), 550-54.

- Constatinou, E. \& Romaniuk, D. (2004). Client Safety. In: Potter P, Perry A, Ross-Kerr, Wood M. Canadian Fundamentals of Nursing. Toronto: Elsevier.

- Day, T., Wainwright, S.P. \& Wilson-Barnett, J. (2001). An evaluation of a teaching intervention to improve the practice of endotracheal suctioning in intensive care units. J ClinNurs. 10(5), 682-96.

- Felix, C.C.P. \& Miyadahira, A.M.K. (2009). Avaliação da técnica de lavagem das mãos executada por alunos do Curso de Graduação em Enfermagem. Rev Esc Enferm USP. 43(1), 139-45.

- Ferreira, A.M., Andrade, D., Almeida, M.T.G., Cunha, K.C. \& Rigotti, M.A. (2011). Colchões do tipo caixa de ovo: um reservatório de Staphylococcus aureus resistente à meticilina? Rev Esc Enferm USP. 45(1), 161-66.

- Galdeano, L.E. (2007). Validação do diagnostico de enfermagem conhecimento deficiente em relação à doença arterial coronariana e a revascularização do miocárdio [tese]. Escola de Enfermagem de Ribeirão Preto: Universidade de São Paulo, Ribeirão Preto.

- Graham, K. \& Logan J. (2004). Using the Ottawa Model of Research use to implement a skin care program. J Nurs Care Qual. 19(1), 18-24.

- Kohn, L.T., Corrigan, J.M. \& Donaldson, M.C. (2000). Committee on Quality of Health Care; Institute of Medicine. To Err is Human: building a safer health system. Washington (DC): National Academy Press.

- Lima, E.D., Fleck, C.S., Borges, J.J.V., Condessa, R.L. \& Vieira, S.R.R. (2013). Efeitos de intervenção educativa na adesão às recomendações técnicas de aspiração traquebrônquica em pacientes internados na unidade de terapia intensiva. Rev Bras Ter Intensiva. 25(2), 115-22.

- Luangasanatip, N., Hongsuwan, M., Limmathurotsakul, D., Lubell, Y., Lee, A.S., Harbarth, S. et al. (2015). Comparative efficacy of interventions to promote hand hygiene in hospital: systematic review and network meta-analysis. BMJ. 351:h3728.

- Martin, G.S. (2012). Sepsis, severe sepsis and septic shock: changes in incidence, pathogens and outcomes. Expert Rev Anti Infect Ther. 10(6), 701-06.

- Mendonça, A.P., Fernandes, M.S.C., Azevedo, J.M.R., Silveira, W.C.R. \& Souza, A.C.S. (2003). Lavagem das mãos: adesão dos profissionais de saúde em uma unidade de terapia intensiva neonatal. Acta Scientiarum Health Scienc. 25(2), 14753.

- Ministério da Saúde do Brasil (Br) Agência Nacional de Vigilância Sanitária [acesso em 16 Fev. 2018]. Assistência Segura: Uma Reflexão Teórica Aplicada à Prática. Brasília: Ministério da Saúde, $2013 . \quad$ Recuperado en https://www20.anvisa.gov.br/segurancadopacient e/images/documentos/livros/Livro1-

Assistencia_Segura.pdf.

- Nair, S. S., Hanumantappa, R., Hiremath, S.G., Siraj, M.A. \& Raghunath, P. (2014). Knowledge, Attitude, and Practice of Hand Hygiene among Medical and Nursing Students at a Tertiary Health Care Centre in Raichur, India. ISRN Preventive Med. (608927): DOI:10.1155/2014/608927.

- Pittet, D., Dharans, S., Touveneau, S., Sauvan, V. \& Perneger, T.V. (1999) Bacterial contamination of the hands of hospital staff during routine patient care. Arch Intern Med. 159(8), 821-26.

- Pittet, D., Hugonnet, S., Harbarth, S., Mourouga, P., Sauvan, V., Touveneau S. et al. (2000). Effectiveness of a hospital-wide programe to improve compliance with hand hygiene. Infection Control Programe. Lancet. 356(9238), 1307-12.

- Rabhe, S.A.N. \& Caliri, M.H.L. (2003). Úlcera de pressão: estratégias para divulgação do conhecimento na literatura de enfermagem. Rev Paul Enferm. 22(3), 307-14.

- Raduenz, A. C., Hoffmann, P., Radunz, V., Dal 
Sasso, G.T.M., Maliska, I.C.A. \& Marck P.B. (2010) Cuidados de enfermagem e segurança do paciente: visualizando a organização, acondicionamento e distribuição de medicamentos com método de pesquisa fotográfica. Rev. Latino-Am. Enfermagem. 18(6), 1045-54.

- Reis, C.T., Martins, M. \& Laguardia, J. (2013). A segurança do paciente como dimensão da qualidade do cuidado de saúde: um olhar sobre a literatura. Ciênc. Saúde Coletiva. 18(7), 2029-36.

- Riccio, G.M.G.E.T., Sampaio, L.A.B.N., Faria, M.D.E.F.G., Caracciolo, L.T., Ribeiro, F.G. \& Cruz, D.M.D.A. (1995). Validação de instrumento de levantamento de dados para a formulação de diagnóstico de enfermagem. Rev. Soc. Cardiol. 5(3), 1-16.

- Sousa, C.M.M., Moura, M.E.B., Santos, A.M.R., Nunes, B.M.V.T. \& Alves, M.S.C.F. (2009). Responsabilidade civil dos profissionais de enfermagem nos procedimentos invasivos. Rev. Bras. Enferm. 62(5), 717-22.
- Thakker, V.S. \& Jadhav, P.R. (2015). Knowledge of hand hygiene in undergraduate medical, dental and nursing students: A cross-sectional survey. $J$ Family Med Prim Care. 4(4), 582-86.

- Tipple, A.F.V., Sá, A.S., Mendonça, K.M., Sousa, A.C.S. \& Santos, S.L.V. (2010) Técnica de higienização simples das mãos: prática entre acadêmicos de enfermagem. Ciencia y Enfermería. 16 (1), 49-58.

- World Health Organization (2009). Guidelines on Hand Hygiene Care: First Global Patient Safety Challenge Clean Care Is Safer Care. Geneva: World Health Organization Press. Recuperado en http://www.who.int/gpsc/5may/tools/97892415979 06/en/.

- Yves, L., Hugo, S., Benedetta, A., Franck, S. \& Didier, P. (2011). Hand higyene. N Engl J Med. 364: e2431 de DOI: 10.1056/NEJMvcm0903599. 